\title{
The possibilities presented by educational technology for educational renewal in South Africa
}

\author{
De la Rey Marais \\ Department of Didactics and Media Science \\ Potchefstroom University for CHE \\ POTCHEFSTROOM
}

\begin{abstract}
With the reality of large-scale political reforms in South Africa and the concomitant restnicturing of educational policy in order to ensure equitable quality education for all South Africans, unprecedented creativity is required of everybody. In South Africa hopes are pinned on the possibilities offered by high-lechnology education media as a possible solution for many of the problems besetting the system. The article foctuses on the possibilities and limitations of cducational media in the unique educational circumstances in South Africa. As a result of the reigning didactic circtunstances in the country it is concluded that it is not necessarily the case that high-technology instructional media will resolve the educational difficulties of South-Africa.
\end{abstract}

\section{INTRODUCITON AND PROBLEM STATEMENT}

With the final abolition of the entrenched racially discriminatory policy of apartheid on ₹ February 1991 by the State President, South Africa is at present marked by change in practically every field of endeavour. In the anticipation of one education department for all citizens of South Africa becoming more and more of a reality, enormous demands will be made on a new educational policy if it eventually has to provide in the demands for the social and economic well-being of the people of the country. Keeping this fact in mind, the Cabinet has already requested the Human Sciences Research Council in June 1980 to investigate various facets of education in the RSA. The most important principle guideline of this study, regarding an educational policy that could be implemented in practice, is that the potential of all the inhabitants of the country has to be realized through the establishment of a programme which would ensure education of equal quality for all population groups. (See the findings of the working group for Educational Principles and Policy as incorporated in the HSCR Research Report (1981).)

With large-scale educational change as envisaged for South Africa with its multicultural groupings, one can speak of a multiplicity of educational dimensions which 
have to be addressed at one and the same time. In this regard Taylor (1987:39) distinguishes the following:

- The development and integration of revised teaching material in the shape of curriculum documents and technologies.

- The implementation of new teaching approaches and strategies.

* The adjustment of views, for example of the school and of the classroom.

According to Taylor these mentioned dimensions of educational change should go along with thorough consideration of the social and cultural state of affairs and needs of the people involved in each of these.

In the main speech of the Minister of National Education on 18 May 1990 it was proposed that an urgent study should be made of a renewal strategy for education in the RSA, and many interested parties were approached for comment. A large variety of practical educational matters were tabled, and a working group under the chairmanship of Prof. J.P. de Lange was constituted to look specifically at the possibilities for educational application offered by technology. This working group formulated their recommendation, as contained in the CUP (Committee of University Principals) circular of 19 June $1990(133 / 90: 17-18)$ as follows:

\begin{abstract}
Although consensus exists that educational technology can never replace the tcacher, it is equally true that such technology can be a vital means of teacher-support and harnessed effectively can lead to more effective teaching. Furthermore, such technology could contribute towards alleviating the problem of severe teacher-shortages in some education departments.
\end{abstract}

In this regard, the working group made the following recommendation:

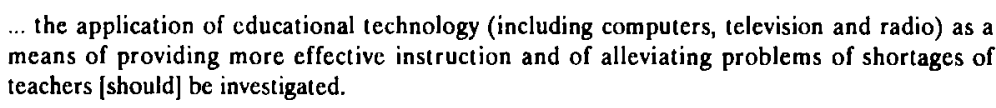

... the application of cducational technology (including computers, television and radio) as a means of providing more effective instruction and of alleviating problems of shortages of teachers [should] be investigated.

Keeping this point of departure and the recommendation of the working group in mind, the following three issues are raised:

* What does the working group mean by educational technology?

* Are we certain that educational media such as computers, television and radio will in general render education more effective - and will they especially ensure that the cultural groups which have been deprived with regard to education will make more rapid progress?

* Is it possible that educational technology will bring relief within the framework of 
the shortage of teachers in certain education departments?

It is subsequently the objective of this article to look briefly at the three stated issues.

\section{EDUCATIONAL TECHNOLOGY}

Educational technology can be seen as the co-ordination of people, resources and materials in such a way that maximum effectiveness will be brought about in teaching and learning. Ely (1972:37) defines educational technology briefly in the following terms by referring to the purpose of this field of study:

The overriding goal and purpose of the field of educational technology is to facilitate and improve the quality of human learning.

The term educational technology is mostly interpreted incorrectly in South Africa, and interpreted as referring only to the apparatus (overhead projectors, computers, sound equipment, etc.) and programme material (video programmes, colour slides, computer programmes, etc.) which can be integrated into a teaching programme in the form of instructional media (Marais, 1990:6). Although the field of educational technology also has to do with the development of apparatus and programmes the field is in actual fact much wider. To explain this more fully, one could regard educational technology in line with the parallels created by mining technology or agricultural technology, where the concerns are much wider than simply the equipment used in these fields of study. Rowntree, (1974:1) put it as follows:

A cynic has remarked that many things have happened in this century and most of them plug into walls. But even if the sockets were to be filled in and the secret of electricity lost for ever, we would still need educational technology. For educational technology is as wide as education itself.

As education has developed in the course of years, also with the aid of educational technology, there has also been the issue of high-technology in the form of educational media such as the micro-computer, television and radio. These developments have further contributed to the phenomenon of educational technology being linked to the development of educational hardware only (Romiszowski, 1986:17). Since man's earliest history he has also made use of 'low-technology' to inculcate learning contents. This technology has to be regarded as the precursor of high-technology instructional media and will always be the backbone of communication in education. Today lowtechnology instructional media can be described as blackboards, books, journals, charts and so on. Seeing that the arts of writing and printing were also regarded as hightechnology in their day, it is thus highly probable that the computer will also, within the 
The possibilities presented by educational technology for educational renewal in S.A.

foreseeable future, begin to be associated with the category of low-technology. Development therefore constantly defines the description of the relevant technology. In looking back over educational development not too many innovations have occurred in the course of decades in the field of traditional teaching, apart from the addition of some 'newer'-generation educational media. What did, however, change dramatically through the new technology such as computers, television and radio has been that it has become much easier for the teaching profession to retrieve and handle data more optimally (in what is known as the information revolution) (Dick \& Reiser, 1989:7). This characteristic of the new-generation educational media brings us to the following problematic issue of this article. Can the integration of computers, video and radio ensure that education in general will be more effective by ensuring above all that the deprived cultural groups in South Africa will profit by it?

\section{THE CONTRIBUTION OF INSTRUCTIONAL MEDIA TO IMPROVED EDUCATION FOR ALL IN SOUTH AFRICA}

Large-scale educational renewal will have to take place in South Africa in the midst of a clash between First World and Third World interests. It is especially among rural blacks that there is a fundamental ignorance regarding the basic skills needed for the effective functioning of a Western-oriented society. This problem is exacerbated by the fact that the Blacks in South Africa is at present in a process of transition between traditional and modern ways of life, and his mode of life reveals traits of both (Hall, 1987:88). The problem is made worse if one keeps in mind that only $29,4 \%$ of all black people in South Africa over the age of 25 (according to Ellis (1986) through an interpretation of the 1980 census) have passed Standard three (fifth grade).

At the other end of the spectrum South Africa presents a 'developed' world of technology and information retrieval which has grown out of a process of ongoing evolutionary development. Cilliers (1987:13) states that

(i)t should be borne in mind that information is the consequence of development and not its cause.

With the wide diversity of cultural and ethnic groups in South Africa Roberts (1987:20) warns against a 'mass-approach' to communication and education. The basic intellectual error which is made is that the total population can be reached through the mass media, and that the mass of people can be seen as individuals who will with the same stimuli respond identically and therefore will learn in the same way.

A second issue which has to be kept in mind is that specific educational media dispose 
of specific and at times limited features (educational possibilities). In this way the computer has good possibilities for evaluation, but as a result of limited graphic possibilities, it has poor projective possibilities. Contrasted to that television has good projective possibilities. Radio, again, is only directed at auditive stimuli. Should this fact be kept in mind one can understand that there is no single medium which will be suitable for the teaching of all learning contents (Kaufman \& Herman, 1991:235). In this way, the computer, video or radio will, for example, only be capable of ensuring limited teaching-learning outcomes. One can therefore not at all speak of a 'super medium'. This 'media-feature' perspective of teaching leads us directly to the third issue, that of cost-effectiveness of various instructional materials.

Gallup (1977:34) explains the concept of cost-effectiveness of instructional media as follows:

Within an instrumental technology context, cost-effectiveness means comparing costs and benefits encountered in utilizing two instructional alternatives to teach the same course content, and then using those comparisons to make decisions on which alternative is the most effective.

Greenhill, as quoted by Gallup (1977:34) mentions the following with regard to costeffectiveness of instructional media which should be kept in mind:

* In instructional media with the same cost the best quality for teaching should be considered. The attitude which the medium elicits in the learners in the form of improved pupil participation, interest, motivation and attitude should also be - considered.

* One should consider

- whether the instructional medium can reach more children at the same level of effectiveness and at the same cost,

- whether the medium can, in the same stretch of time, transmit more learning contents as effectively,

- whether the medium uses up less physical space and

- whether the instructional medium can guide pupils with a lower or more varied work input to a satisfactory standard of work.

Physical aspects such as the teaching-learning environment (the school), the level to which the instructional media have advanced, the encoding potential of media, functioning and reliability, availability and technical support will be further factors 
which will co-determine the choice of technology with regard to cost-effectiveness in education.

In response to the question as to whether high-technology instructional media will lead to better education in South Africa, the answer is a qualified yes, but only if aspects such as learning content, teaching group composition, didactic time and cost-effectiveness are taken into account. Seeing that the focus of education in South Africa will in the near future mainly be directed at the upliftment of the deprived population groups, a high premium will be placed on the development of a unique approach to the selection and integration of instructional media in education.

\section{THE CONTRIBUTION OF EDUCATIONAL TECHNOLOGY TO EDUCATIONAL SHORTAGES}

Should educational technology be seen as the co-ordination of people, resources and material in a planned approach to problem-solution, this field of study offers the only hope for excellence in educational renewal in South Africa. Should educational technology, however, be reduced in people's perceptions to apparatus in the form of computers, television and radio, the picture becomes a bleak one and hope diminishes, seeing that it has not to date been proved that high-technology instructional media have led to improved or even the same level of learning as ordinary class teaching. Schramm (1977:28) has said the following about this issue:

\footnotetext{
We conclude from evidence that, overall, there is no basis in the research for saying that students learn more or less from television than from classroom teaching.
}

This does not mean that under some conditions of teaching some students do not learn more of certain subject matter or skills from one medium or channel of teaching than from the other. The results of the broad comparisons, however, say that there is, in general, no significant difference.

\section{CONCLUSIONS AND RECOMMENDATIONS}

Based on consideration of a large variety of didactic aspects, the following conclusions and recommendations can be made:

The majority of people in decision-making positions in education in South Africa have the perception that educational technology is concerned only with the apparatus and programmes which can be applied for educational purposes. They also reveal an exag- 
gerated sense of optimism that specific kinds of apparatus will bring the deprived Black rural cultural groups to the same level of education as White cultural groups.

Before a policy with regard to the selection of instructional media (in the form of computer equipment and so forth) can be made, curriculum development for both the formal and the non-formal education in South Africa should be well advanced. This aspect is important because of the diversity of cultural groups and social needs in the Republic of South Africa.

Seeing that maximal learning occurs when the learning and living conditions of the pupils coincide, it is to be doubted whether a 'high-technology' approach will, without further ado, lead to a solution for the mentioned educational problems in South Africa. Should one look more closely at the unique and sometimes limited and cost-ineffective media characteristics of instructional media such as micro-computers, one realizes that all levels of education will not benefit from this kind of technology. 'High-technology media literacy' is a developmental process involving time, and in many cases it will only create further confusion rather than make a contribution to effective teaching and learning. In this regard Hall (1987:80) points out that the radio has an advantage over television as a medium of instruction among Blacks in rural areas. The implementation of especially micro-computers in education with a view to solving the above problems should be approached with the greatest circumspection. This is not to say, however, that there are not some target groups which will benefit by the implementation of this technology.

As a result of the differences of content in the different subjects, one can refer to subject-typical learning contents demanding typical approaches in teaching. This leads to the realization that not every kind of medium will of necessity be suitable for any kind of subject. It has the further implication that the value of specific high-technology instructional media will in some regards be totally over-emphasized in South Africa. On the other hand the true value of low-technology educational media will then be under-emphasized. Should the composition of South Africa's learning public be evaluated in terms of aspects such as numbers, cultural differentiation, social environment and locality, the development of low-technology instructional media should, at this stage of the process of renewal, enjoy preference. Educational media of great importance include textbooks for pupils, source books for teachers, study guides and journals. Other low-technology instructional media such as blackboards and overhead projectors, should be developed together with the establishment of basic educational infrastructures such as classrooms.

In rural areas the integration of high-technology educational media becomes a greater problem because of the lack of the most basic infrastructure, such as few or no 
classrooms, no electricity and large numbers, as well as the cost involved. In this regard one could look at the establishment of networks of information centres (teachers' centres). Further development of and increasing responsibility for existing centres should be considered, as well as the establishment of technical support services and media programme development, production and evaluation. In-service training with a view to the transmission of skills to people of the immediate environment should enjoy preferential consideration in the form of low-technology. In this way the shortage of teachers could, as a starting-point, be alleviated in the short term.

Distance teaching through the establishment of the necessary low-technology teaching material (for example, course books, workbooks and class books) can be undertaken by educational institutions identified for this purpose. High-technology educational media can work in the form of (radio) broadcasts. In this regard Hall (1987:85) refers to the necessity for radio-listening groups which can be brought about in co-ordinated fashion.

As a result of cultural differences, where especially mother-tongue education, norms and values, customs and habits are strong considerations, aspects such as the "translation' of high-technology programme material should be seen as of paramount importance. Pictorial material is especially important in this regard because symbolic representations might assume different meanings for different cultural groups. 'Actors' and representations of the social environment within pictorial material are therefore very important for teaching and learning. What is in reality being said here, is that the instructional material which will be suitable for one group will not necessarily be useful for another, seeing that the needs of the different cultural groups differ so much.

\section{RECAPITULATION}

In the first instance it should be realized that a number of didactic considerations such as curriculum development, target group analysis, nature and complexity of learning contents, grouping norms, a large variety of physical aspects and cost-effectiveness play a role in choices of technological issues in education. As a result of the reigning didactic circumstances in South-Africa it is therefore not necessarily the case that hightechnology instructional media will resolve the educational difficulties in the country. The damage done by a unique approach to education has in the course of decades become too deeply ingrained to be resolved rapidly. 


\section{BIBLIOGRAPHY}

CILLIERS, I. 1987. The Impact of the Information Society. (In a Discussion with the Future.) RSA 2000, 9(2):13-17.

DICK, W. \& REISER, R.A. 1989. Planning Effettive Instruction. New Jersey : Prentice Hall.

ELLIS, C.S. 1986. Literacy Statistics in the RSA, 1980. Pretoria. HSRC Research Report.

ELY, D.P. 1972. The Field of Educational Technology: A Statement of Definition. Audiovisual Instruction, 17(18):1-3.

GALLUP, D.A. 1977. Determining the Cost-Effectiveness of Instructional Technology. Educational Technology, XVII(2):34- 37 .

HALL, MA. 1987. The Utilization of Radio-Listening Groups for Health Education in a Developing Community. RTV, 1(3):80-91.

HSRC RESEARCH REPORT 1981. Report of Working Committee: Educational Principles and Policy. Pretoria. (Investigation of education.)

CUP. 1990. Education Renewal Strategy: Request for Inputs. (Circular 133/90.)

KAUFMAN, R. \& HERMAN, J. 1991. Strategic Planning in Education. Pennsylvania : Technomic.

MARAIS, D. 1990. The Contribution of Teaching Media to Effective Differentiated Teaching. Pretoria. HSRC Research Report.

ROBERTS, D.F. 1987. Television in the Information Revolution. (In Discussion with the Future.) RSA $2000,9(2): 18-23$.

ROMISZOWSKI, A.J. 1986. Developing Auto-Instructional Materials. London : Kogan Page.

ROWNTREE, D. 1974. Educational Technology in Curriculum Development. London : Harper \& Row.

SCHRAMM, W. 1977. Big Media Little Media. London : Sage.

TAYLOR, C.A. 1987. Strategies for the Implementation of Large-Scale Educational Change. RTV, 1(3):39- 47. 
